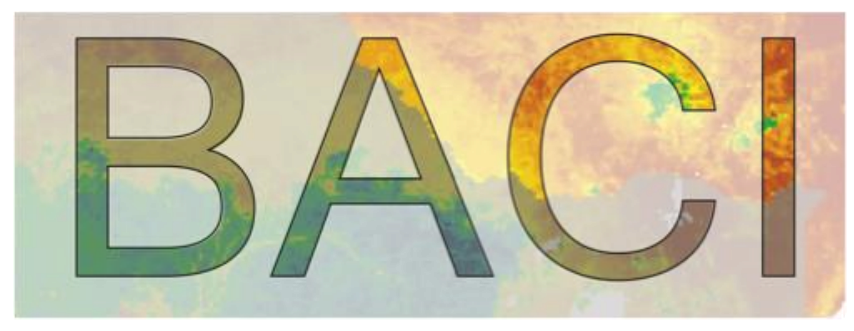

\title{
Differentiating drought legacy effects on vegetation growth over the temperate Northern Hemisphere
}

\section{Postprint version}

Wu, X., Liu, H., Li, X., Ciais, P., Babst, F., Guo, W., et al.

\section{Published in: Global Change Biology}

This is the peer reviewed version of the following article:

Reference: Wu, X., Liu, H., Li, X., Ciais, P., Babst, F., Guo, W., et al. (2018).

Differentiating drought legacy effects on vegetation growth over the temperate Northern Hemisphere. Global Change Biology, 24(1), 504-516. doi:10.1111/gcb.13920

which has been published in final form at:

Web link: https://onlinelibrary.wiley.com/doi/full/10.1111/gcb.13920

This article may be used for non-commercial purposes in accordance with Wiley Terms and Conditions for Use of Self-Archived Versions. 


\title{
Differentiating drought legacy effects on vegetation growth over the temperate Northern Hemisphere
}

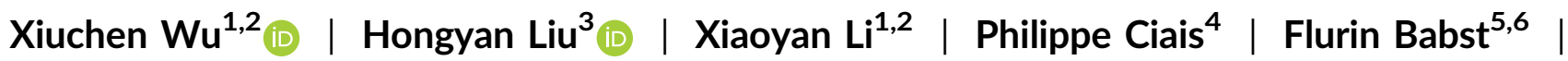 \\ Weichao Guo ${ }^{3}$ | Cicheng Zhang ${ }^{2}$ | Vincenzo Magliulo ${ }^{7}$ | Marian Pavelka ${ }^{8}$ | \\ Shaomin Liu, ${ }^{1,2}$ Yongmei Huang ${ }^{1,2}$ | Pei Wang ${ }^{1,2}$ | Chunming Shi ${ }^{1,9}$ | Yujun Ma ${ }^{1,2}$
}

${ }^{1}$ State Key Laboratory of Earth Surface Processes and Resource Ecology, Beijing Normal University, Beijing, China

${ }^{2}$ Faculty of Geographical Science, Beijing Normal University, Beijing, China

${ }^{3}$ College of Urban and Environmental Science, Peking University, Beijing, China

${ }^{4}$ CEA-CNRS-UVSQ, UMR8212-Laboratoire des Sciences du Climat et de I'Environnement (LSCE), Gif-Sur-Yvette, France

${ }^{5}$ Dendro Sciences, Swiss Federal Research Institute WSL, Birmensdorf, Switzerland

${ }^{6} \mathrm{~W}$. Szafer Institute of Botany, Polish Academy of Sciences, Krakow, Poland

${ }^{7}$ National Research Council of Italy, Institute for Mediterranean Agriculture and Forest Systems (CNR-ISAFoM), Ercolano, Italy

${ }^{8}$ CzechGlobe-Global Change Research Institute CAS, Brno, Czech Republic

${ }^{9}$ College of Global Change and Earth System Science, Beijing Normal University, Beijing, China

\section{Correspondence}

Xiaoyan Li, Faculty of Geographical Science, Beijing Normal University, Beijing, China. Email: xyli@bnu.edu.cn

\section{Funding information}

Schweizerischer Nationalfonds zur

Förderung der Wissenschaftlichen Forschung, Grant/Award Number: P300P2_154543; National Natural Science Foundation of China, Grant/Award Number: 41390462, 41530747, 41571038; State Key Laboratory of Earth Surface Processes and Resource Ecology, Grant/Award Number: 2017-ZY-06; EU Horizon-2020, Grant/ Award Number: 640176

\begin{abstract}
In view of future changes in climate, it is important to better understand how different plant functional groups (PFGs) respond to warmer and drier conditions, particularly in temperate regions where an increase in both the frequency and severity of drought is expected. The patterns and mechanisms of immediate and delayed impacts of extreme drought on vegetation growth remain poorly quantified. Using satellite measurements of vegetation greenness, in-situ tree-ring records, eddy-covariance $\mathrm{CO}_{2}$ and water flux measurements, and meta-analyses of source water of plant use among PFGs, we show that drought legacy effects on vegetation growth differ markedly between forests, shrubs and grass across diverse bioclimatic conditions over the temperate Northern Hemisphere. Deep-rooted forests exhibit a drought legacy response with reduced growth during up to 4 years after an extreme drought, whereas shrubs and grass have drought legacy effects of approximately 2 years and 1 year, respectively. Statistical analyses partly attribute the differences in drought legacy effects among PFGs to plant eco-hydrological properties (related to traits), including plant water use and hydraulic responses. These results can be used to improve the representation of drought response of different PFGs in land surface models, and assess their biogeochemical and biophysical feedbacks in response to a warmer and drier climate.
\end{abstract}

\section{KEYWORDS}

drought legacy effect, drought resilience, ecohydrological responses, extreme drought, plant functional groups, rooting system, stomatal conductance, vegetation growth 


\section{1 | INTRODUCTION}

Climate warming causes an increase in atmospheric water demand and terrestrial evapotranspiration (Greve et al., 2014; Novick et al., 2016; Trenberth et al., 2014; Will, Wilson, Zou, \& Hennessey, 2013), which may profoundly change the soil water resources available for vegetation growth. Changes in precipitation are spatially less coherent than those of temperature, but a majority of climate models project a reduction across the temperate northern latitudes with a strong decrease in moderate rainfall events (IPCC, 2013, Lau, Wu, \& Kim, 2013; Sheffield \& Wood, 2008). This warming-induced drought trend, known as "global-change-type" drought (Breshears et al., 2005), is largest and most variable in midlatitudes (hereafter, $30^{\circ}-50^{\circ} \mathrm{N}$ ) of northern hemisphere (NH) (Dai, 2011; IPCC, 2013) and is expected to decrease soil moisture (SM) supply for vegetation cover and productivity. Furthermore, warming-induced drought may become more severe in already-drier regions, owing to the "dry become drier and wet become wetter" empirical hypothesis (Skliris, Zika, Nurser, Josey, \& Marsh, 2016) coupled with an intensified water cycle (Huntington, 2006; Skliris et al., 2016).

Drought considerably alters ecohydrological processes (e.g., increased vapor pressure deficit [VPD], SM depletion, stomatal conductance reduction) within the soil-plant-atmosphere continuum (SPAC) on time scales ranging from hours to years (Bréda, Huc, Granier, \& Dreyer, 2006; Novick et al., 2016; Van Der Molen et al., 2011) and can thus profoundly affect both the functioning and structure of ecosystems. The projected climate change may further exacerbate climatic drought in the northern midlatitudes, but large uncertainties remain regarding the spatial distribution of total precipitation amount and changes in the frequency of rainfall events (Lau et al., 2013; Orlowsky \& Seneviratne, 2013). Differences between climate models and scenarios are thereby coupled with differences in modeled SM-temperature interactions in land surface models (Mueller \& Seneviratne, 2012). The spatiotemporal responses of vegetation growth and productivity to changes in drought conditions have been analyzed empirically (Allen, Breshears, \& McDowell, 2015; Beer et al., 2010; Gaylord, Kolb, \& McDowell, 2015; Liu et al., 2013; Vicente-Serrano et al., 2013) and for case studies of extreme drought events (Ciais et al., 2005; Reichstein et al., 2007; Wolf et al., 2016). Increasing evidence suggests that terrestrial vegetation photosynthesis and growth are more negatively affected by extreme drought events (pulse disturbance) than by gradual changes in mean drought conditions (press disturbance) (Barbeta et al., 2015; Ciais et al., 2005; McDowell et al., 2008). Extreme drought events can not only result in an immediate reduction in canopy photosynthesis, but also have long-lasting lagged effects on vegetation growth (Anderegg et al., 2015; McDowell et al., 2008). Consequences range from loss of carbohydrate reserves to hydraulic failure and forest mortality, as well as increased risk of pest/pathogen attacks (Allen et al., 2010, 2015; Breshears et al., 2005). Such drought-induced vegetation changes add large uncertainty to predictions of terrestrial ecosystem responses to climate change, with diverse impacts on hydrological budgets, carbon balance, and ecosystem services (Anderegg et al., 2013; Gaylord et al., 2015). Problematically, our physiological understanding of how vegetation growth responds to extreme drought events is limited at large spatiotemporal scales (Craine et al., 2013).

Only recently have the lagged effects of extreme drought on plant growth/productivity been documented for woody and herbaceous plants from field experiments and large-scale syntheses relying on tree ring observations and remote sensing retrievals (Anderegg et al., 2013, 2015; Barnes et al., 2016; Sala, Gherardi, Reichmann, Jobbagy, \& Peters, 2012; Vicente-Serrano et al., 2013). Tree-ring measurements thereby revealed a pervasive legacy of 1-4 years on tree growth after severe drought events that was particularly pronounced in water-limited regions and for species with low hydraulic safety margins (Anderegg et al., 2015). By contrast, other PFGs respond to extreme drought in a different manner, as illustrated by the time-scale analysis of drought response from Vicente-Serrano et al. (2013).

This study aims to quantify and compare drought legacy effects on vegetation growth for different northern temperate PFGs, with a focus on extreme drought effects. Extreme drought events are determined by twofold standard deviation dry anomaly (i.e., $-2 S D$ ) of synthetic drought index or calculated Climatic Water Deficit (CWD) variables (see Section 2). Specifically, we ask: (1) whether there are consistent drought legacy effects in different PFGs; and (2) how eco-hydrological properties explain potential differences in drought legacy effects among different PFGs. We address these two questions using remote sensing observations of the Normalized Difference Vegetation Index (NDVI), tree-ring measurements, and FLUXNET eddy-covariance observations of water and energy fluxes for forests, shrubs and grass over the temperate $\mathrm{NH}$. We thereby focus on interannual rather than intra-annual legacy effects because the latter have recently been documented (Barnes et al., 2016; Novick et al., 2016).

\section{2 | MATERIALS AND METHODS}

\section{1 | Vegetation growth, climate, and land cover datasets}

\subsection{1 | NDVI dataset}

The latest version of the biweekly NDVI dataset from Advanced Very High Resolution Radiometer observations during 1982-2013 was obtained from the Global Inventory Modeling and Mapping Studies (GIMMS) group (i.e., GIMMS NDVI3g). The GIMMS NDVI3g dataset has a spatial resolution of $0.083^{\circ}$ and was aggregated to a spatial resolution of $0.5^{\circ}$ to match the climate data (see below). This dataset has been processed accounting for calibration loss, orbital drift, sensor degradation, intersensor differences, cloud cover, zenith angle, and volcanic aerosols (Pinzon \& Tucker, 2014). It has been widely used to characterize land cover and monitor spatiotemporal changes in vegetation activity/ 
productivity in response to climate variations and extreme events (e.g., drought), both regionally and globally (Gonsamo, Chen, \& Lombardozzi, 2016; Piao et al., 2014; Wu et al., 2015, 2016). Previous studies showed that GIMMS NDVI3g time series can well capture the interannual lag effects of climate variability and extreme drought events on regional vegetation growth across diverse climate zones (Richard et al., 2008; Williams et al., 2013; $\mathrm{Wu}$ et al., 2015). Annual mean growing-season NDVI for the period of 1982-2013 was calculated, with the growing-season defined as the April-October period. Regions with multiyear mean annual NDVI values below 0.1 during 1982-2013 were discarded from final analyses.

\subsection{2 | Land cover dataset}

The classifications of three natural PFGs over temperate $\mathrm{NH}$ are based on the Moderate Resolution Imaging Spectroradiometer land cover product MOD12C1 (http://glcf.umd.edu/data/lc/), which identifies 17 land cover classes defined by the International GeosphereBiosphere Program (IGBP) scheme. Specifically, we grouped the widely distributed categories evergreen needleleaf forest, deciduous needleleaf forest, deciduous broadleaf forest and mixed forest over temperate $\mathrm{NH}$ as "forest", given the distribution of evergreen broadleaf forest over temperate $\mathrm{NH}$ is quite limited. We grouped the categories closed shrublands, open shrublands, woody savannas, and savannas as "shrub". Grassland in MOD12C1 is regarded as "grass" (Fig. S1).

\subsection{3 | Tree Ring Index chronologies}

Raw tree-ring width data from 549 sites across the temperate $\mathrm{NH}$ (Fig. S1) were obtained from the International Tree Ring Data Bank (http://www.ncdc.noaa.gov/data-access/paleoclimatology-data/data sets/tree-ring) on January 1, 2016. The individual tree-level series that constitute these records include 88 species of evergreen needleleaf forest, deciduous needleleaf forest and deciduous broadleaf forest types (Table S1) over temperate $\mathrm{NH}$, cover $\sim 18,000$ siteyears during 1965-2013, and span diverse bioclimatic conditions. Our selection criteria for the retained sites included: (1) basic information on latitude, longitude, elevation, species name, and sample depth; (2) a minimum series length of 25 years between 1965 and 2013; and (3) a sample number (individual tree cores) for each siteyear greater than five. As our study focuses on interannual to decadal growth variability, we removed longer term (non-) climatic signals embedded in the raw ring-width measurements by means of a cubic smoothing spline detrending with a 50\% frequency-response threshold of 20 years. The raw ring-width measurements were divided by the corresponding fitted spline values, resulting in a unitless tree-ring index (TRI). The tree-level TRI were averaged into site-level chronologies using a biweight robust mean. With this procedure, we removed the low- to medium-frequency variability in TRI chronologies but retained the high-frequency variability and the first-order autocorrelation.

\subsubsection{Climate datasets and drought variables}

In the absence of a universal definition and metric of drought across diverse bioclimatic conditions, we calculated three different CWD metrics from datasets of precipitation, potential evapotranspiration (PET), and SM as follows: (1) Precipitation of Climatic Research Unit (CRU, http://www.cru.uea.ac.uk/) minus PET of CRU (CRU-PET) calculated using the Penman-Monteith approach (hereafter as CWDCRU); (2) Precipitation of Global Precipitation Climatology Center (GPCC) minus CRU-PET (hereafter as CWD-GPCC); and (3) Land-surface model simulated SM of the Climate Prediction Center (CPC, http://www.cpc.ncep.noaa.gov/products/Soilmst_Monitoring/US/ Soilmst/Soilmst.shtml) (Fan \& Van Den Dool, 2004) minus CRU-PET (hereafter as CWD-SM).

We also use the Standard Precipitation-Evapotranspiration Index (SPEI) database, SPElbase V2.4 (http://sac.csic.es/spei/database. $\mathrm{html}$ ), to identify extreme drought events. The SPElbase V2.4 covers the period of 1901-2014 and incorporates monthly information on both temperature and precipitation at a spatial resolution of $0.5^{\circ}$. The SPEI across multiple time-scales (i.e., 1-48 months) provides consistent information on spatiotemporal patterns in drought conditions and has been used in previous drought impact analysis (Vicente-Serrano et al., 2013). We used the three different CWD fields and mean growing season SPEI with a time-scale of 3 months to identify extreme drought events during 1982-2013 in each grid over temperate $\mathrm{NH}$. This time-scale was chosen because vegetation growth in this region responds predominantly to mean annual SPEI within time scales of 2-4 months (Vicente-Serrano et al., 2013).

\subsection{Ecosystem surface conductance and VPD at FLUXNET sites}

We calculated mean growing-season (April-October) ecosystem surface conductance $\left(g_{s}\right)$ at 65 FLUXNET sites (in total 321 site years) over the temperate NH (Fig. S1) from the La Thuile Synthesis Dataset (http://fluxnet.fluxdata.org/data/la-thuile-dataset/) to define the response of $g_{s}$ to drought across vegetation types within different Köppen-Geiger climate zones. The selected FLUXNET sites cover nine different vegetation types in the IGBP classification used in MOD12C1 (Table S2). Daily $g_{s}$ was calculated by inverting the Penman-Monteith equation for each site-year using daily mean measurements of latent heat flux, sensible heat flux, relative humidity (RH) and net radiation. We then averaged daily $g_{s}$ over the growing season. Site-years with more than $20 \%$ missing observations of either climate variables or eddy-covariance fluxes over a growing season were excluded. Mean growing-season VPD for each site-year was calculated based on observed air temperature $(T)$ and $\mathrm{RH}$, as illustrated in Equations (1) and (2),

$$
\mathrm{VPD}=\left(1-\left(\frac{\mathrm{RH}}{100}\right)\right) \times \mathrm{SVP},
$$

where, SVP (in unit of $\mathrm{Pa}$ ) is the saturated vapor pressure for a given temperature $T$ (in unit of ${ }^{\circ} \mathrm{C}$ ), as calculated by Equation (2), 


$$
\mathrm{SVP}=610.7 \times 10^{7.5 T /(237.3+T)}
$$

\section{3 | Statistical analyses}

\subsection{1 | Relationships between vegetation growth, $g_{s}$ and drought variables}

Vegetation growth across most of the temperate $\mathrm{NH}$ is limited by water availability (Jung et al., 2017). In this study, Pearson's correlation and linear regression are applied to quantify the strength of the interannual relationship between vegetation growth represented by mean growing-season NDVI [NDVI $\mathrm{GS}_{\text {] }}$ and TRI and different drought metrics. Nonlinear exponential regressions are used (if applicable) to investigate the relationship between mean growing-season $g_{s}$ and VPD for different vegetation types over selected FLUXNET sites. Such relationships are compared between and constrained within three major climate zones: temperate arid region (RegTA), temperate humid region (RegTH), and cold humid region (RegCH) (Table S1) to better understand the response of $g_{s}$ to VPD variations across diverse bioclimatic conditions.

\subsection{2 | Drought legacy and drought resilience in vegetation growth}

Similar to Anderegg et al. (2015), we defined extreme drought legacy in vegetation growth as a departure (unitless) of the observed vegetation growth (represented by $\mathrm{NDVI}_{\mathrm{GS}}$ and TRI) from predicted vegetation growth in a period ranging 1-4 years after an extreme drought event. Only single drought events (no consecutive drought within 4 years after a -2 SD dry anomaly) lasting no more than 1 year were considered. The "predicted" vegetation growth in 1-4 years after each extreme drought event was calculated by linear regressions over the entire period of overlap between TRI and/ or $\mathrm{NDVI}_{\mathrm{GS}}$ and different drought variables. Informative prediction of legacy response of vegetation growth after extreme drought events depends on the strength (i.e., the goodness) of the linear regressions between vegetation growth and drought variables (see Section 3). All vegetation growth measures and drought variables were normalized prior to linear regressions.

Interannual variations in vegetation growth over the temperate $\mathrm{NH}$ is primarily driven by water condition, so that the drought metrics alone explain a large part of the variability in vegetation growth. We compared drought legacy effects in forests, shrubs and grass, derived from (1) all available grid points and (2) only from grid points with significantly positive relationships $(p<.05)$ between vegetation growth and drought metrics. Drought legacy effects for different PFGs were quantified as the difference between observed and predicted vegetation growth after a $-2 S D$ drought event over the following 1-4 years, averaged across all extreme drought events in $\mathrm{NDVI}_{\mathrm{GS}}$ or TRI. A bootstrapped sampling method with 1,000 replications was applied to estimate confidence intervals around the drought legacy effects in 1-4 years after extreme drought events for all three PFGs over the temperate $\mathrm{NH}$.

To test if nonclimatic drivers (e.g., $\mathrm{CO}_{2}$ fertilization, nutrient availability changes, or disturbance history) bias our quantification of drought legacy effects, two additional analyses were performed. First, we developed a null model following Anderegg et al. (2015) where exactly the same calculation is performed to quantify false legacy effects by examining growth anomalies after randomly selected drought years instead of after $-2 S D$ dry anomalies. We kept the same number of false drought events in vegetation growth (NDVI $\mathrm{GS}_{\mathrm{G}}$ and/or TRI) in each grid, so that each grid is weighted similarly with the false and the true drought occurrences. Second, we detrended the $\mathrm{NDVI}_{\mathrm{GS}}$ series during 1982-2013 in each grid point over temperate NH using a linear detrending method with turning point based on Annual Aggregated Time Series in greenbrown $\mathrm{R}$ package. In the detrended time series, a maximum of one turning point is allowed in each grid over the span of each time series (see also Forkel et al., 2013).

To investigate the linkage between drought legacy effects and drought resilience of vegetation among different PFGs, a mean vegetation growth resilience $\left(R_{s}\right)$ indicator is calculated to represent changes in vegetation growth after a severe drought event, as given by:

$$
R_{s}=G_{\text {post }}-G_{\text {prev }}
$$

where, $G_{\text {post }}$ and $G_{\text {prev }}$ is the mean detrended vegetation growth (NDVI GS or TRI) at a period of 1-3 years after and before severe drought events (hereafter time-scales of $1-3$ ). A negative $R_{s}$ value represents a growth reduction after an extreme drought event. Probability density function (PDF) of $\triangle \mathrm{NDVI}_{\mathrm{GS}}, \Delta \mathrm{TRI}$ (i.e., the difference between the predicted and observed $\mathrm{NDVI}_{\mathrm{GS}}$ and TRI) and Rs were diagnosed to quantify the distribution of drought legacy effects in different periods after severe drought events and vegetation growth resilience at different time-scales for different PFGs.

\section{3 | RESULTS}

\section{1 | Interannual relationship between vegetation growth and drought}

We investigated spatial patterns in the linear relationship between vegetation growth (represented by $\mathrm{NDVI}_{\mathrm{GS}}$ and TRI) and the four drought metrics. Pearson's correlation and linear regression analyses show that both $\mathrm{NDVI}_{\mathrm{GS}}$ and TRI are closely related to the four drought metrics over the vegetated temperate $\mathrm{NH}$, and exhibit similar spatial pattern in this relationship, albeit with greatly varying strength (Figures 1 and 2, Figs S2 and S3). Significantly positive correlation between $\mathrm{NDVI}_{\mathrm{GS}}$ and each of the four drought metrics was observed over $48 \%-\sim 55 \%$ of the study region, with mean Pearson's correlation coefficients ranging between $0.36 \pm 0.28-0.45 \pm 0.31$ (Figure 1). Positive correlations between $\mathrm{NDVI}_{\mathrm{GS}}$ and drought variables higher than $0.35(p<.05)$ are predominant in central and southwestern North America, Mediterranean-type regions, and central Eurasia (Figure 1).

The linear regression models account for $28 \pm 13 \%$ to $35 \pm 15 \%$ of the interannual variation in $\mathrm{NDVI}_{\mathrm{GS}}$ across grid-points for different 
drought metrics during 1982-2013 (Fig. S2). Consistently, more than $60 \%$ of TRI series show significantly positive correlation with at least one of the four drought metrics (Figure 2); however drought only explains $\sim 27 \%-32 \%$ of the interannual variations in TRI during the period 1965-2013 (Fig. S3). Both NDVI $\mathrm{GS}_{\mathrm{G}}$ and TRI show stronger relationships with the SPEI and with the CWD-SM indexes than with the two other CWD indices (Figures 1 and 2).

\subsection{Longer drought legacy effects for forests compared to shrubs and grass}

We analyzed drought legacy effects on the growth of forests, shrubs, and grass, averaging all extreme drought events based on $\mathrm{NDVI}_{\mathrm{GS}}$ series for different drought metrics during 1982-2013. The same analysis was performed for TRI. Legacy effects on $\mathrm{NDVI}_{\mathrm{GS}}$ in the first year after extreme drought are observed in $65 \%-74 \%$ of the grid points with significantly positive correlation between $\mathrm{NDVI}_{\mathrm{GS}}$ and drought metrics (Fig. S4). There are consistent patterns of 1-4 year legacy effects on forest growth among the four drought metrics (Figure 3a). Drought legacy effects differ markedly between the three PFGs (Figure 3a) and are more evident in grid points with a significantly positive relationship between vegetation growth and drought variables for all three PFGs (Fig. S4). Drought legacy effects on forests are consistently longer than 1 year and can last up to 4 years. By contrast, the maximum drought legacy is 2 years for shrubs and 1 year for grass (Figure 3a). Legacy effects on vegetation growth at periods of 1-4 years after an extreme drought with the detrended $\mathrm{NDVI}_{\mathrm{GS}}$ series (see Section 2) are consistent with those obtained from raw NDVI $\mathrm{GS}$ time series (Fig. S5). Importantly, a different lag-time of legacy effects between forests, shrubs, and grass, is not reflected in the null model (Fig. S6), increasing our confidence that this result is not a statistical artifact.

\section{3 | Comparing legacy effects deduced from $\mathrm{NDVI}_{\mathrm{GS}}$ vs. TRI for forest}

The drought legacy effects on forest growth derived from $\mathrm{NDVI}_{\mathrm{GS}}$ and TRI are compared in Figure 3a,b. The NDVI-based legacy effects
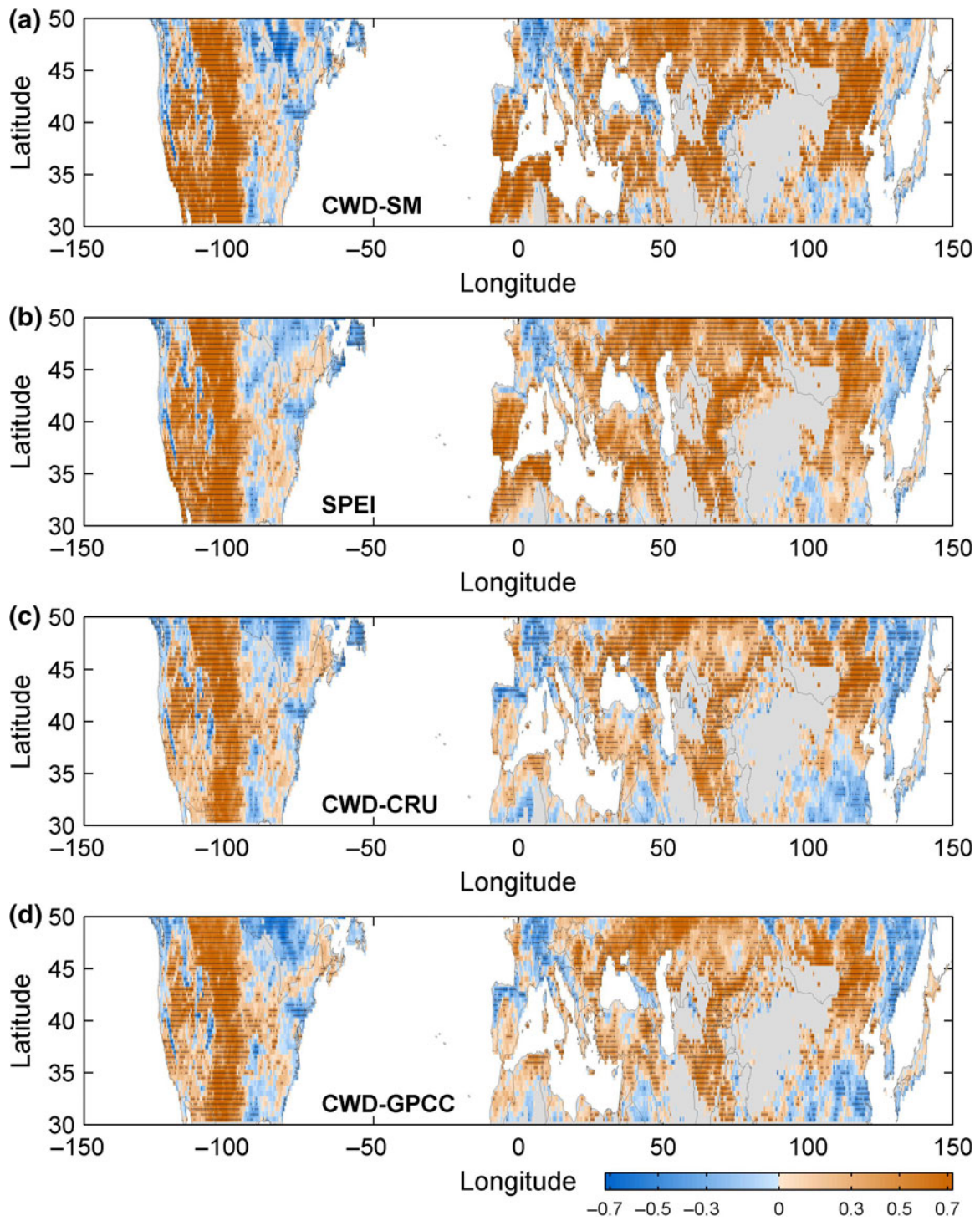

FIGURE 1 Spatial patterns in Pearson's correlation coefficients between mean growing-season (April-October) Normalized Difference Vegetation Index ( $\mathrm{NDVI}_{\mathrm{GS}}$ ) and mean growing-season drought conditions during 1982-2013. Mean growing-season drought conditions are evaluated by Standard Precipitation-Evapotranspiration Index (SPEI) and Climatic Water Deficit calculated as precipitation of Climatic Research Unit (CRU, http://www.cru. uea.ac.uk/) minus potential evapotranspiration of CRU (CWD-CRU), precipitation of Global Precipitation Climatology Center (GPCC) minus PET of CRU (CWD-GPCC), and soil moisture of Climate Prediction Center (CPC) minus PET of CRU (CWD-SM). Stratified regions in (ad) indicate statistically significant relationship between $\mathrm{NDVI}_{\mathrm{GS}}$ and four drought variables $(p<.05)$. Gray regions indicate the multiyear mean NDVI values $<0.1$ during 1982-2013 and are excluded from our final analyses 

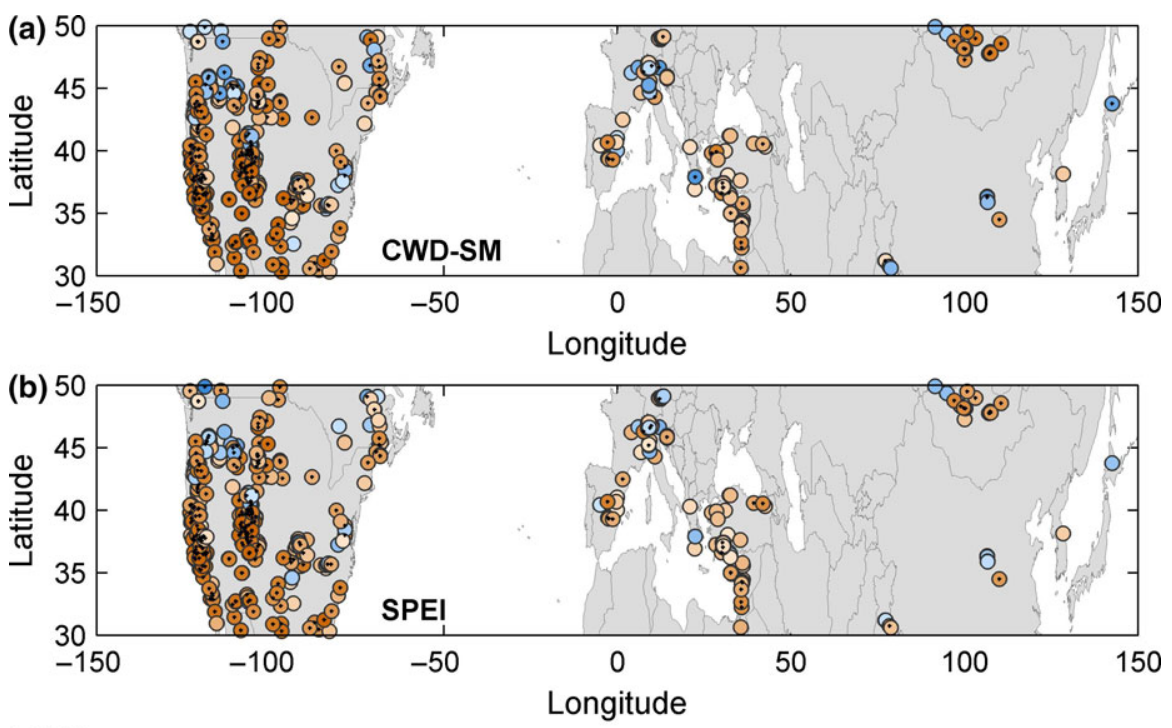

FIGURE 2 Spatial pattern in the Pearson's correlation coefficients between tree ring index (TRI) and mean growingseason drought conditions during 1965-2013. Mean growing-season drought conditions are evaluated by Standard Precipitation-Evapotranspiration Index (SPEI) and Climatic Water Deficit calculated as precipitation of Climatic Research Unit (CRU, http://www.cru. uea.ac.uk/) minus potential evapotranspiration of CRU (CWD-CRU), precipitation of Global Precipitation Climatology Center (GPCC) minus PET of CRU (CWD-GPCC), and soil moisture of Climate Prediction Center (CPC) minus PET of CRU (CWD-SM). Stratified points indicate statistically significant relationship between TRI and drought variables $(p<.05)$
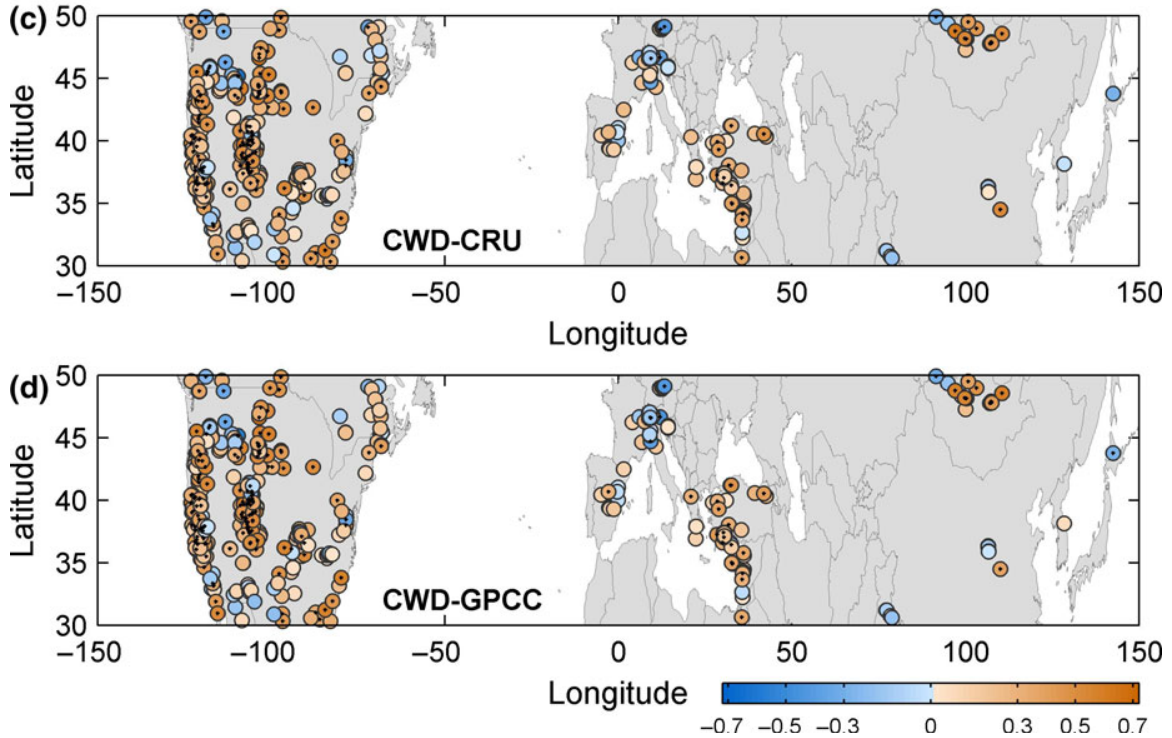

are largely in agreement with those derived from TRI, despite apparent differences in TRI-based legacy effects between the different drought metrics (Figure 3b). Drought legacy effects on TRI are more prominent with CWD-CRU and CWD-GPCC than with the other two drought metrics. PDF analyses reveal large spatial variations in the NDVI-based legacy effects at different lags after extreme droughts. $65 \%-69 \%$ of the $\mathrm{NH}$ temperate forest exhibits a larger negative $\triangle \mathrm{NDVI}_{\mathrm{GS}}$ (observed minus predicted $\mathrm{NDVI}_{\mathrm{GS}}$ ) in the 1-2 years compared to 3-4 years after extreme drought (Figure $4 a$, b). PDF analyses show that TRI-based drought legacy effects on forest growth at different periods post drought vary among different species/sites over temperate NH (Figure 4c,d).

\section{4 | Drought resilience differences between forests, shrubs and grass}

Here we compare the drought resilience $\left(R_{s}\right)$ of vegetation growth based on $\mathrm{NDVI}_{\mathrm{GS}}$ between forests, shrubs and grass on time-scales of $1-3$ years before/after extreme drought events. For shrubs, we found consistent negative $R_{s}$ values at time-scales of $1-3$ years, whereas for grass, a negative $R_{s}$ at time-scale of 1 year but positive $R_{s}$ at time-scale of 2-3 years was observed. For forest, no negative $R_{s}$ is found on time-scales of $1-3$ years, indicating a stronger resilience of this PFG. Instead, there is a positive $R_{s}$ for forest on timescale of 2-3 years in the grid-cells with significant and positive relationships between $\mathrm{NDVI}_{\mathrm{GS}}$ and SPEI (Figure 5).

\section{DISCUSSION}

\subsection{Differentiating drought legacy effects on vegetation growth of different PFGs}

Our finding that forests experience longer drought legacies than other PFGs is consistent with previous studies in both temperate and boreal forests, suggesting drought legacies ranging between 1-4 years that are particularly pronounced in water-limited regions (Anderegg et al., 2015; Pederson et al., 2014; Peltier, Fell, \& Ogle, 2016). Extreme drought events result in incomplete and lagged forest growth 

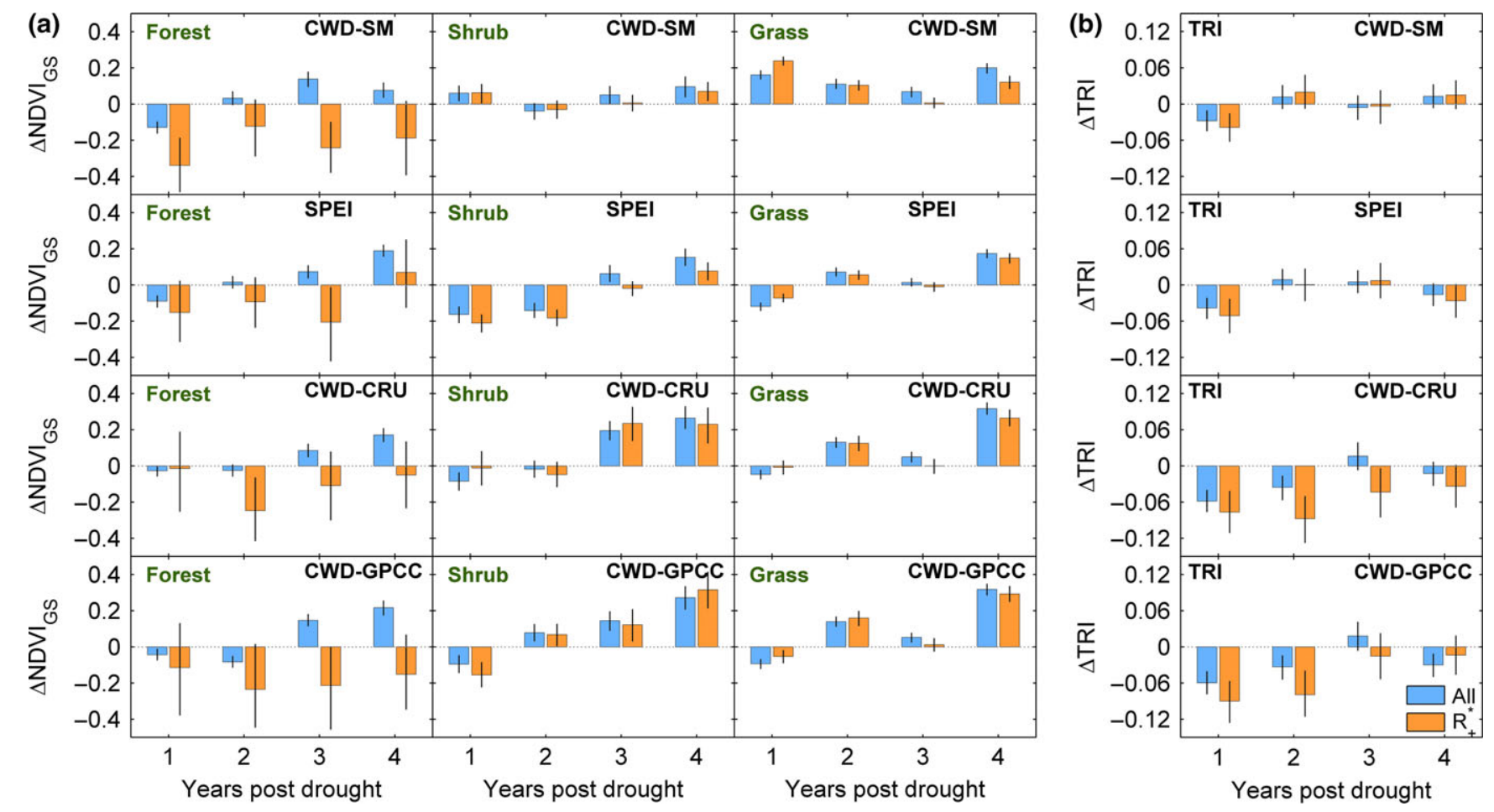

FIGURE 3 Drought legacy effects in mean growing-season Normalized Difference Vegetation Index (NDVI GS $_{\text {) }}(\mathrm{a})$ and TRI (b) at periods of 1-4 years after extreme drought events over vegetated temperate Northern Hemisphere. Four different kinds of drought variables are analyzed, including a Standard Precipitation-Evapotranspiration Index (SPEI), and climatic water deficit calculated as precipitation of Climatic Research Unit (CRU, http://www.cru.uea.ac.uk/) minus potential evapotranspiration of CRU (CWD-CRU), precipitation of Global Precipitation Climatology Center (GPCC) minus PET of CRU (CWD-GPCC), and soil moisture of Climate Prediction Center (CPC) minus PET of CRU (CWDSM). Error bars indicate $95 \%$ confidence intervals of drought legacy effects on vegetation growth at different periods after extreme drought events. Blue and orange bars show results from all available grids/chronologies (All) and grids/chronologies with significant and positive correlation $\left(R_{+}^{*}\right)$ between $\mathrm{NDVI}_{\mathrm{GS}} / \mathrm{TRI}$ and drought variables

recovery and/or increased canopy disturbance (e.g., crown defoliation) (Anderegg et al., 2015; Pederson et al., 2014). Large-scale extreme drought events can even synchronize regional forest responses or trigger lagged forest mortality (Pederson et al., 2014; Vanoni, Bugmann, Notzli, \& Bigler, 2016). Our analyses of remote sensing data are also consistent with field experiments showing an approximate drought legacy of 1-2 years on shrub growth (Jobbágy \& Sala, 2000). Grass recovers rapidly from drought and a legacy effect is only detectable within a maximum time lag of 1 year in semiarid regions (Arnone et al., 2008; Arredondo et al., 2016). For instance, evidence from Chihuahuan desert grasslands shows that previousyear precipitation explains only $20 \%$ of current-year net primary production (Reichmann and Sala, 2014) and this effect is attributable to the production of storage organs (e.g., buds) that sustains consequent growth. We note, however, that our remote sensing-based classification of grass at coarse spatial resolution did not distinguish between annual and perennial grass. Hence, we cannot reliably quantify uncertainties in the calculation of drought legacy effects on grass growth that are attributable to potential differences in the drought responses of annual and perennial grass (i.e., the effects of lifespan). Previous studies revealed that annual grass is generally more sensitive to and responds much rapidly to drought events than perennial grass (Copeland et al., 2016; Tilman \& El Haddi, 1992).
The fact that, despite spatial variations among or even within bioclimatic regions (Breshears et al., 2005; Peltier et al., 2016), we found clear differences in drought legacies between PFGs raises fundamental questions regarding the underlying mechanisms. Differences in drought severity among PFGs could play an important role, but we found no significant spatial relationship between the accumulative legacy effects over the first 3 years after drought events within or among any of the three PFGs ( $p>.05$ of student's $t$ test) (Fig. S7). This suggests that the observed differences in legacy effects between PFGs are not likely attributable to the differences in drought severity.

Instead, we argue here that these differences arise from different eco-hydrological and physiological responses to drought (Breshears et al., 2005), as well as from spatial heterogeneity in hydrothermal conditions (Anderegg et al., 2015). Firstly, differences among PFGs regarding foliage loss and/or nonstructural carbohydrate depletion during severe drought events may impair vegetation recovery in subsequent years (Bréda et al., 2006; Vesk \& Westoby, 2003), particularly for perennial vegetation (Anderegg et al., 2013; Dobbertin, 2005; Guada, Camarero, Sanchez-Salguero, \& Cerrillo, 2016). Local field experiments have shown that both the patterns and magnitude of leaf loss and/or stem damage vary greatly among different plant species, and are linked to plant traits including leaf mass per area 
FIGURE 4 Mean drought legacy effects and the probability density function (PDF) of drought legacy effects on mean growing-season NDVI (NDVI GS) and TRI at periods of $1-4$ years after extreme drought events. Drought condition is represented by a Standard PrecipitationEvapotranspiration Index (SPEI). Data show here are derived from grids with significant and positive correlations between mean $\mathrm{NDVI}_{\mathrm{GS}} / \mathrm{TRI}$ and SPEI. Error bars in (a) and (c) represent $95 \%$ confidence intervals estimated using bootstrapped method with 1,000 replications
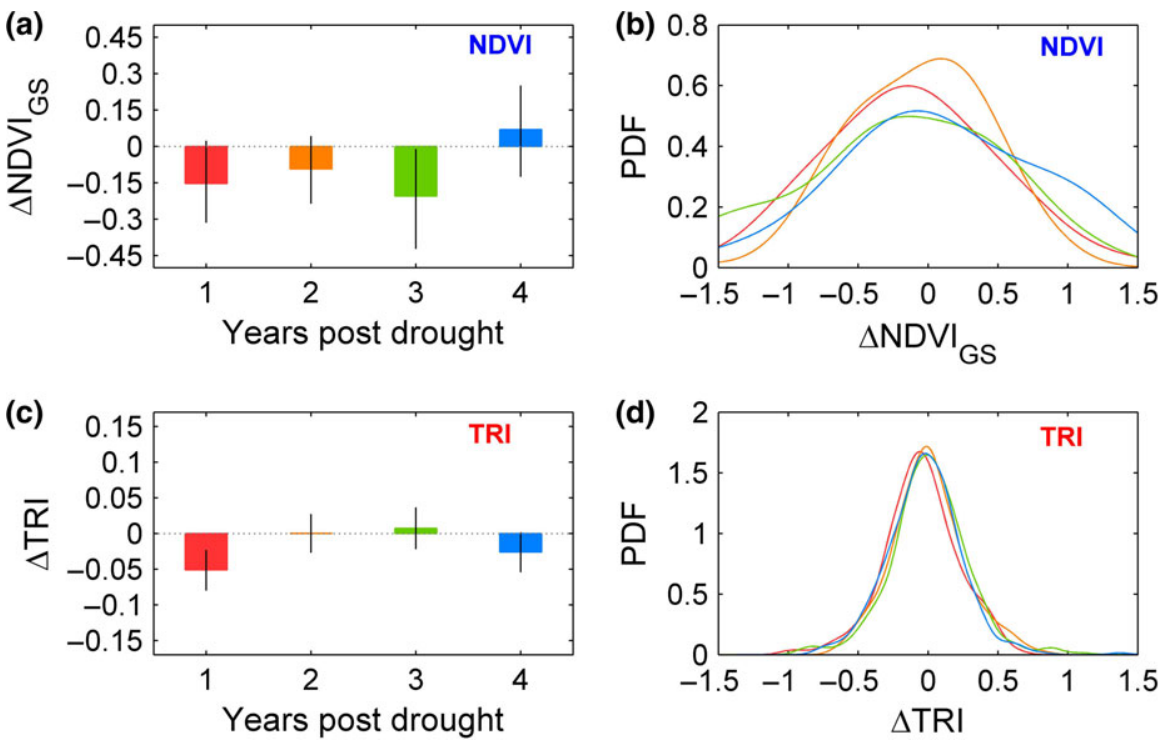

and sapwood density (Vesk \& Westoby, 2003). However, testing this mechanism across diverse PFGs and bioclimatic conditions is hampered by a scarcity of field observations. Another potential cause is drought-induced hydraulic dysfunction (cavitation) impairing ecohydrological connectivity within SPAC and resulting in lagged drought effects. However, the eco-hydrological consequences in response to extreme drought events may differ among PFGs, owing to (1) different rooting systems and related water use patterns, and (2) different ecohydraulic responses to drought.

\subsection{Rooting system and water use patterns}

Plants in water-limited regions can adapt to dry environments by accessing ground water (Craine et al., 2013), which retains previous rainfall and buffers vegetation growth against drought (Gazis \& Feng, 2004; Mahmood \& Vivoni, 2014). Accessibility of ground water depends on the root systems (depth and density, see also Figure 8). Shallow-rooted grass normally takes up available soil water from top-middle soil (Figure 6, Table S3), where SM variations quickly
FIGURE 5 Mean growth resilience $\left(R_{s}\right)$ and the probability density function (PDF) of growth resilience in forests, shrubs and grass in response to extreme drought events at different time-scales. Drought events are estimated by a Standard Precipitation-Evapotranspiration Index (SPEI). Growth resilience for forests, shrubs and grass is calculated at time-scales ranging $1-3$ years based on mean growing-season NDVI (NDVI $I_{\mathrm{GS}}$ ). Different time-scales indicate different length of consecutive years before and after extreme drought events considered for calculation of $R_{s}$. $\mathrm{NDVI}_{\mathrm{GS}}$ is detrended by a linear method prior to $R_{S}$ (unitless) calculation. Error bars represent $95 \%$ confidence intervals estimated by bootstrapped method with 1,000 replications
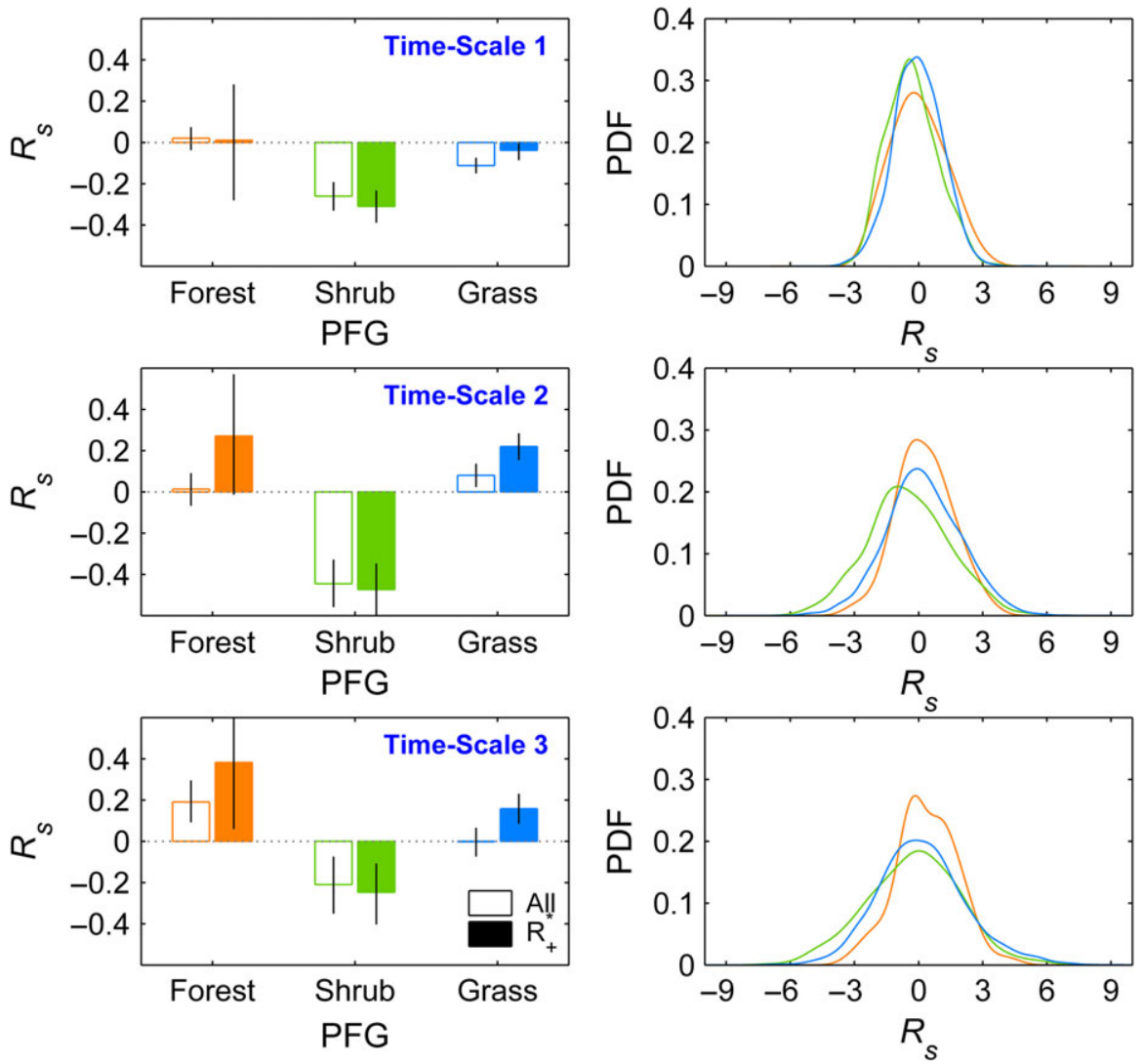


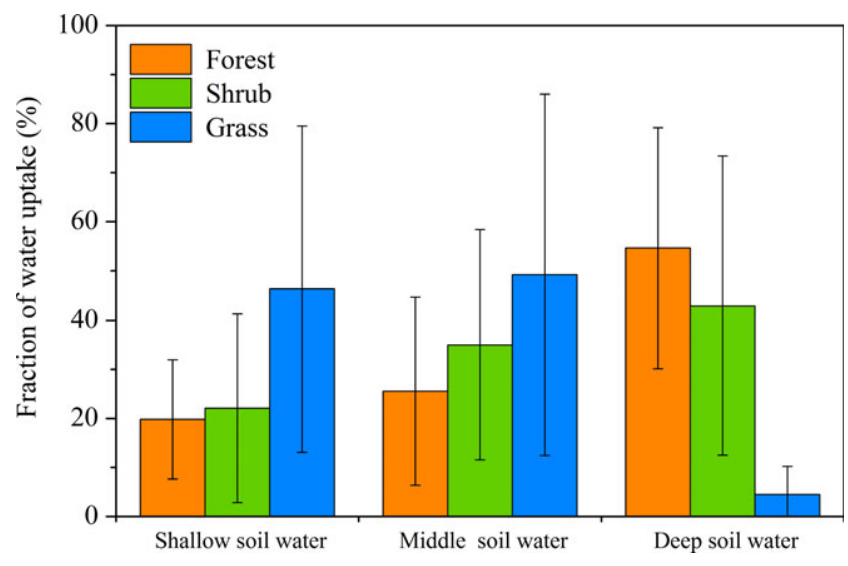

FIGURE 6 Mean fraction of soil water uptake from different soil layers in forests, shrubs and grass over temperate Northern Hemisphere. Three different soil layers are roughly defined here, with shallow, middle, and deep layer corresponding to $0-20 / 30 \mathrm{~cm}$, $20 / 30-50 / 70 \mathrm{~cm},>50 / 70 \mathrm{~cm}$ respectively. Note that the definitions for shallow, middle and deep layers are quite different among different studies (for details see Table S3)

responds to precipitation pulses (Sala, Lauenroth, \& Parton, 1992). This could explain the fast response of grass growth to even small rewetting events after severe drought in grasslands of the temperate $\mathrm{NH}$. However, grass organs store too little water and carbon to maintain growth during and after severe drought and lead to negative $R_{s}$ in the first year after a severe drought (Figure 5). By contrast, deep-rooted forests can continue to take up available water from deep soil during extreme drought events (Schwinning, Starr, \& Ehleringer, 2005; Teuling et al., 2010) (see Figure 8). The deep soil is usually incompletely replenished until a subsequent extreme wet event or postwinter snow melting (Jipp, Nepstad, Cassel, \& De Carvalho, 1998; Phillips, 2010; Tang \& Feng, 2001; Yaseef, Yakir, Rotenberg, Schiller, \& Cohen, 2010), which probably results in prolonged drought periods for deep-rooted plants and thus lagged growth impacts (Breshears et al., 2005). Shrubs can take up soil water adaptively from top to deep soil layers (Figure 6), with increased use of top-soil water under nondrought stress and a tendency of using water from deeper soil under drought stress. Such differentiating water use pattern can also explain the reported negative correlation between plant sizes and severe drought-induced damage (Lloret \& Granzow-De La Cerda, 2013). However, both the patterns and drivers of the residence time of soil water in diverse soil layers and pools (with varying sizes) across large gradients of hydrothermal conditions have not been well quantified.

\section{3 | Hydraulic responses to drought}

Hydraulic responses to drought and their consequences may also partly explain the different drought legacies among different PFGs. Such responses are most evident at the leaf and xylem levels. Field experiments have shown that the grass leaf water potential is less variable than the soil water potential in response to drought, implying that grass is tolerant to drought (Arredondo et al., 2016). Indeed, grass in temperate and arid regions shows a low but wide range of stomatal conductance (Figure 7a), indicating a potentially high diversity of drought tolerance (Craine et al., 2013). In contrast, Darcy's law predicts that taller plants are more vulnerable to drought (McDowell \& Allen, 2015), even though tall woody plants may have more drought resistant xylem systems. Forests in cold humid regions in temperate $\mathrm{NH}$ show a quicker loss of surface conductance in response to increased VPD than grass in temperate humid region (Figure 7b,c). However, surface conductance of forests in temperate regions does not show an obvious decrease with increasing VPD (Figure 7a,b).

Differences among or within PFGs in stomatal conductance in response to severe drought is closely linked to severe drought imposed plant hydraulic damage (e.g., loss of hydraulic conductivity) (Bartlett, Klein, Jansen, Choat, \& Sack, 2016). Rapid stomatal closure
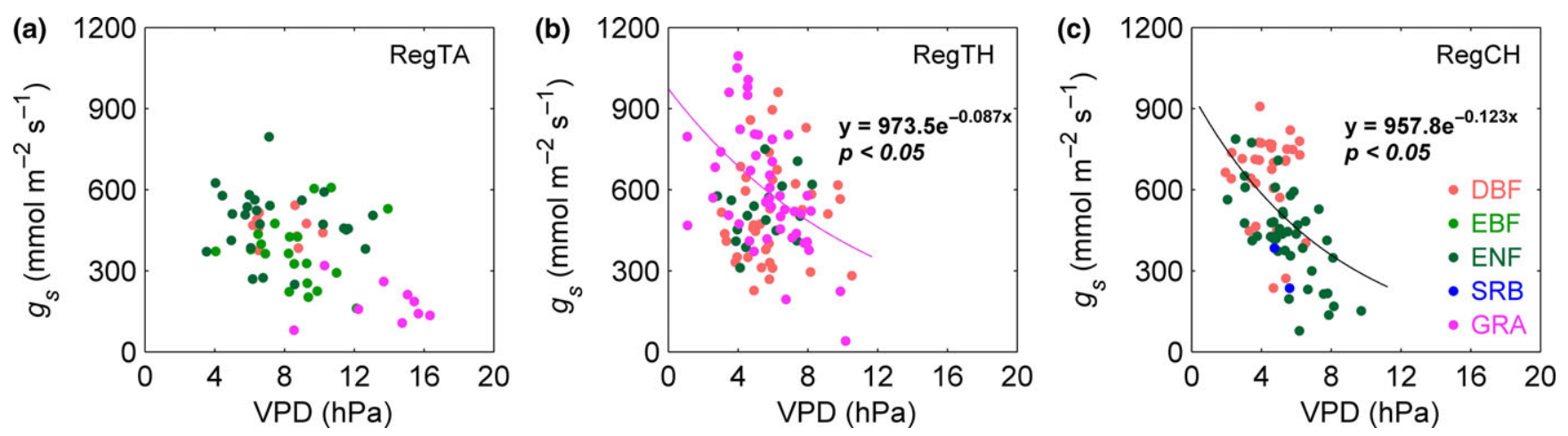

FIGURE 7 Relationships between mean growing-season (April-October) vapor pressure deficit (VPD) and ecosystem surface conductance $\left(g_{s}\right)$ for different vegetation types over temperate Northern Hemisphere. The relationship between VDP and $g_{s}$ for deciduous broadleaf forest (DBF), evergreen broadleaf forest (EBF), evergreen needle leaf forest (ENF), shrub (SRB) and grass (GRA) ecosystems in temperate arid (RegTA, a), temperate humid (RegTH, b) and cold humid $(\operatorname{Reg} C H, c)$ regions is investigated. The line in b and $c$ is the exponential fitted line $(p<.05)$ for the relationship between VDP and $g_{s}$ for grass in RegTH and forest in RegCH, respectively. The VPD and $g_{s}$ data is derived from the LaThuile FLUXNET Synthesis Dataset (http://fluxnet.fluxdata.org/data/la-thuile-dataset/). Each point represents a site-year, whereas site-years with bad gaps ( $>=20 \%$ of total growing season length) of either VPD or $g_{s}$ are excluded from this analyses 


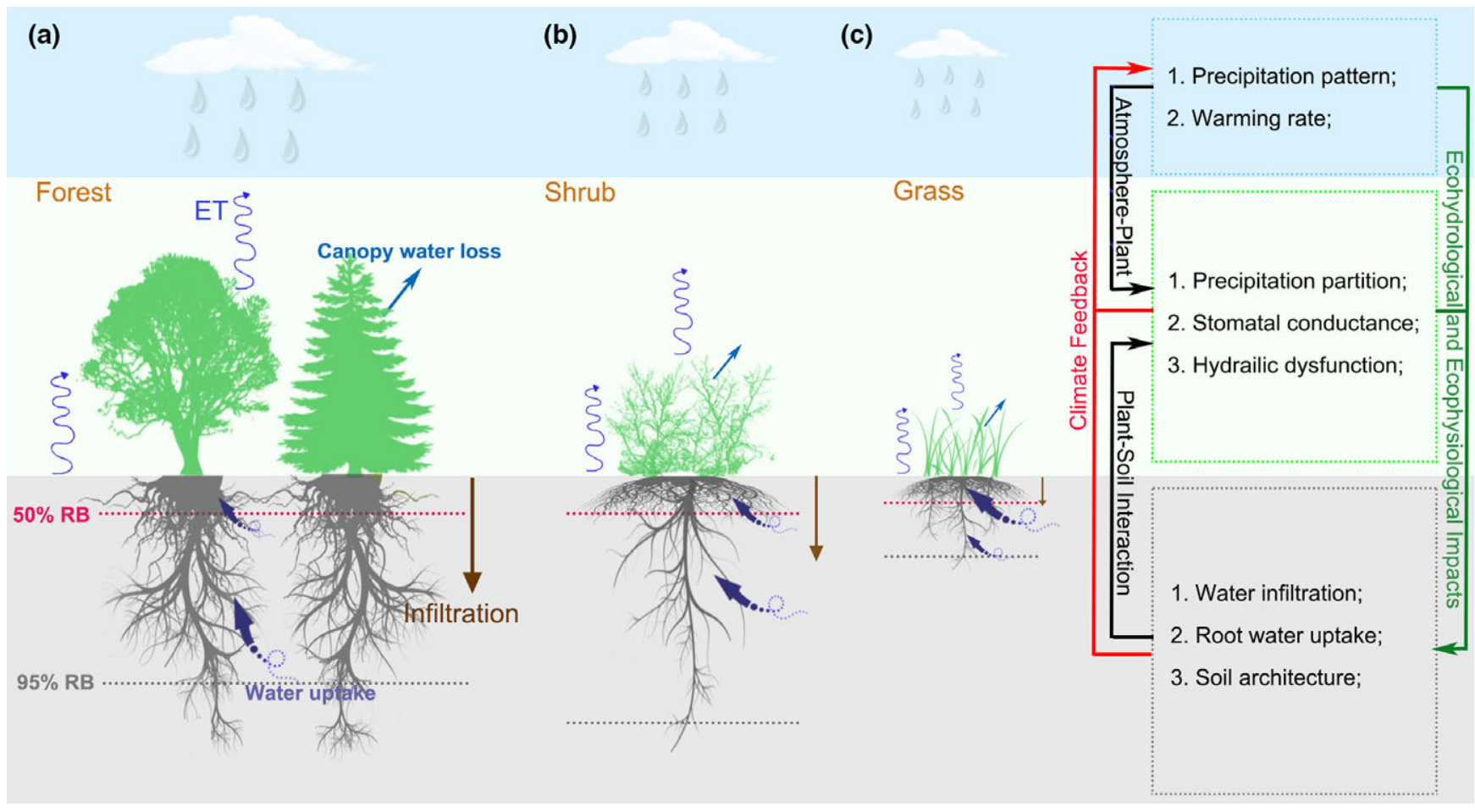

FIGURE 8 Conceptual diagram for the different drought legacy effects on vegetation growth among different plant functional groups after severe drought events. The red and gray numbers and dotted lines indicate the mean soil depth at which $50 \%$ and $95 \%$ root biomass reached for different plant functional groups based on meta-analyses of Schenk \& Jackson (2002)

in response to extreme drought in forests in less drought-prone regions could reflect a high xylem vulnerability to embolism (Lin et al., 2015). A recent study confirmed that stomatal performance is significantly correlated with stem hydraulic vulnerability across different PFGs (Bartlett et al., 2016). Differences in recovery from hydraulic dysfunction across different PFGs may also introduce diverse drought legacy effects in vegetation growth (Zwieniecki \& Holbrook, 2009). The coordination of stomatal sensitivity to drought stress with hydraulic vulnerability across different PFGs could potentially explain the diversity of drought legacy effects.

Longer drought legacy effects in forests do not necessarily cause weaker drought resilience (i.e., much larger reduction in forest growth after drought). Instead, we observe a stronger drought resilience (i.e., smaller growth reduction after severe drought) in forests (Gazol, Camarero, Anderegg, \& Vicente-Serrano, 2017) than shrubs and grass at time-scales ranging 1-3 years. Yet, explicit reasons for long drought legacy but strong drought resilience in forest cannot be tested by our analyses. The complex intrinsic linkage between different stomatal behaviors in response to drought and the observed diverse drought legacy effects among different PFGs needs further quantification. How drought legacy effects and drought resilience will mechanistically interact among diverse PFGs in a warmer climate remains a further big challenge.

In summary, we found significantly longer drought legacy effects on forests than on shrubs and grass, but the mechanisms underlying these differences still remain unclear. Nevertheless, our analyses together with previous findings indicate that divergent drought legacy effects may be linked to the interactive roles of bioclimatic status and hydraulic performance of different PFGs in response to extreme drought (Figure 8). On one hand, deep-rooted forests can access larger soil water pools than shrubs and grass; different water availability and use can thus contribute to diverse lagged effects on plant growth (Figure 8). On the other hand, different hydraulic responses to extreme drought, including surface conductance and plant hydraulic dysfunction, among different PFGs may also play a role. The projected shifts in bioclimatic conditions and related plant physiological adaptation can modify the legacy effects of drought and thus affect the susceptibility of terrestrial ecosystems to climate extremes (Reichstein et al., 2013). Improved understanding of the interaction between drought legacy effects and terrestrial drought resilience is urgently needed to better predict trajectories of terrestrial ecosystems in response to a warmer and drier climate over the temperate $\mathrm{NH}$.

\section{ACKNOWLEDGEMENTS}

We thank the two anonymous reviewers for their constructive comments and suggestions for improving this manuscript. We greatly thank all contributors to the La Thuile synthesis of eddy covariance observations. We thank all investigators for the individual eddy covariance flux sites, particularly the Ameriflux, EuroFlux, and AsiaFlux. X.L. acknowledges funding from National Science Foundation of China (grant \#41390462 and \#91425301). X.W. is founded by the National Science Foundation of China (grant \#41571038 and 
\#41530747) and Project Supported by State Key Laboratory of Earth Surface Processes and Resource Ecology (grant \#2017-ZY-06). F.B. acknowledges funding from the Swiss National Science Foundation (grant \#P300P2_154543) and the EU Horizon-2020 program (grant \#640176, "Detecting changes in essential ecosystem and biodiversity properties - toward a Biosphere Atmosphere Change Index: BACI").

\section{ORCID}

Xiuchen Wu (iD http://orcid.org/0000-0003-0396-7439

Hongyan Liu (D) http://orcid.org/0000-0002-6721-4439

\section{REFERENCES}

Allen, C. D., Breshears, D. D., \& McDowell, N. G. (2015). On underestimation of global vulnerability to tree mortality and forest die-off from hotter drought in the Anthropocene. Ecosphere, 6, 1-55.

Allen, C. D., Macalady, A. K., Chenchouni, H., Bachelet, D., McDowell, N., Vennetier, M., ... Cobb, N. (2010). A global overview of drought and heat-induced tree mortality reveals emerging climate change risks for forests. Forest Ecology and Management, 259, 660-684.

Anderegg, W. R. L., Plavcova, L., Anderegg, L. D. L., Hacke, U. G., Berry, J. A., \& Field, C. B. (2013). Drought's legacy: Multiyear hydraulic deterioration underlies widespread aspen forest die-off and portends increased future risk. Global Change Biology, 19, 1188-1196.

Anderegg, W. R. L., Schwalm, C., Biondi, F., Camarero, J. J., Koch, G., Litvak, M., ... Pacala, S. (2015). Pervasive drought legacies in forest ecosystems and their implications for carbon cycle models. Science, 349, 528-532.

Arnone, J. A. III, Verburg, P. S. J., Johnson, D. W., Larson, J. D., Jasoni, R. L., Lucchesi, A. J., .. Schimel, D. S. (2008). Prolonged suppression of ecosystem carbon dioxide uptake after an anomalously warm year. Nature, 455, 383-386.

Arredondo, T., Garcia-Moya, E., Huber-Sannwald, E., Loescher, H. W., Delgado-Balbuena, J., \& Luna-Luna, M. (2016). Drought manipulation and its direct and legacy effects on productivity of a monodominant and mixed-species semi-arid grassland. Agricultural and Forest Meteorology, 223, 132-140.

Barbeta, A., Mejía-Chang, M., Ogaya, R., Voltas, J., Dawson, T. E., \& Peñuelas, J. (2015). The combined effects of a long-term experimental drought and an extreme drought on the use of plant-water sources in a Mediterranean forest. Global Change Biology, 21, 1213-1225.

Barnes, M. L., Moran, M. S., Scott, R. L., Kolb, T. E., Ponce-Campos, G. E., Moore, D. P., ... Dore, S. (2016). Vegetation productivity responds to sub-annual climate conditions across semiarid biomes. Ecosphere, 7, e01339. https://doi.org/10.1002/ecs2.1339

Bartlett, M. K., Klein, T., Jansen, S., Choat, B., \& Sack, L. (2016). The correlations and sequence of plant stomatal, hydraulic, and wilting responses to drought. Proceedings of the National Academy of Sciences of the United States of America, 113, 13098-13103.

Beer, C., Reichstein, M., Tomelleri, E., Ciais, P., Jung, M., Carvalhais, N., ... Papale, D. (2010). Terrestrial gross carbon dioxide uptake: Global distribution and covariation with climate. Science, 329, 834-838.

Bréda, N., Huc, R., Granier, A., \& Dreyer, E. (2006). Temperate forest trees and stands under severe drought: A review of ecophysiological responses, adaptation processes and long-term consequences. Annals of Forest Science, 63, 625-644.

Breshears, D. D., Cobb, N. S., Rich, P. M., Price, K. P., Allen, C. D., Balice, R. G., ... Meyer, C. W. (2005). Regional vegetation die-off in response to global-change-type drought. Proceedings of the National
Academy of Sciences of the United States of America, 102, 15144 15148.

Ciais, P., Reichstein, M., Viovy, N., Granier, A., Ogée, J., Allard, V., ... Valentini, R. (2005). Europe-wide reduction in primary productivity caused by the heat and drought in 2003. Nature, 437, 529-533.

Copeland, S. M., Harrison, S. P., Latimer, A. M., Damschen, E. I., Eskelinen, A. M., Fernandez-Going, B., ... Thorne, J. H. (2016). Ecological effects of extreme drought on Californian herbaceous plant communities. Ecological Monographs, 86, 295-311.

Craine, J. M., Ocheltree, T. W., Nippert, J. B., Towne, E. G., Skibbe, A. M., Kembel, S. W., \& Fargione, J. E. (2013). Global diversity of drought tolerance and grassland climate-change resilience. Nature Climate Change, 3, 63-67.

Dai, A. (2011). Characteristics and trends in various forms of the Palmer Drought Severity Index during 1900-2008. Journal of Geophysical Research: Atmospheres, 116, D12115. https://doi.org/10.1029/ 2010JD015541

Dobbertin, M. (2005). Tree growth as indicator of tree vitality and of tree reaction to environmental stress: A review. European Journal of Forest Research, 124, 319-333.

Fan, Y., \& Van Den Dool, H. (2004). Climate Prediction Center global monthly soil moisture data set at 0.5 resolution for 1948 to present. Journal of Geophysical Research: Atmospheres, 109, D10102. https://doi.org/10.1029/2003JD004345

Forkel, M., Carvalhais, N., Verbesselt, J., Mahecha, M. D., Neigh, C. S. R., \& Reichstein, M. (2013). Trend change detection in NDVI time series: Effects of inter-annual variability and methodology. Remote Sensing, 5, 2113-2144.

Gaylord, M. L., Kolb, T. E., \& McDowell, N. G. (2015). Mechanisms of pinon pine mortality after severe drought: A retrospective study of mature trees. Tree Physiology, 35, 806-816.

Gazis, C., \& Feng, X. (2004). A stable isotope study of soil water: Evidence for mixing and preferential flow paths. Geoderma, 119, 97-111.

Gazol, A., Camarero, J. J., Anderegg, W. R. L., \& Vicente-Serrano, S. M. (2017). Impacts of droughts on the growth resilience of Northern Hemisphere forests. Global Ecology and Biogeography, 26, 166-176.

Gonsamo, A., Chen, J. M., \& Lombardozzi, D. (2016). Global vegetation productivity response to climatic oscillations during the satellite era. Global Change Biology, 22, 3414-3426.

Greve, P., Orlowsky, B., Mueller, B., Sheffield, J., Reichstein, M., \& Seneviratne, S. I. (2014). Global assessment of trends in wetting and drying over land. Nature Geoscience, 7, 716-721.

Guada, G., Camarero, J. J., Sanchez-Salguero, R., \& Cerrillo, R. M. N. (2016). Limited growth recovery after drought-induced forest dieback in very defoliated trees of two pine species. Frontiers in Plant Science, 7, 418. https://doi.org/10.3389/fpls.2016.00418

Huntington, T. G. (2006). Evidence for intensification of the global water cycle: Review and synthesis. Journal of Hydrology, 319, 83-95.

IPCC (2013) Climate Change 2013: The Physical Science Basis: Working Group I Contribution to the Fifth Assessment Report of the Intergovernmental Panel on Climate Change. Cambridge, UK: Cambridge University Press.

Jipp, P. H., Nepstad, D. C., Cassel, D., \& De Carvalho, C. R. (1998). Deep soil moisture storage and transpiration in forests and pastures of seasonally-dry Amazonia. In A. Markham (Ed.), Potential impacts of climate change on tropical forest ecosystems (pp. 255-272). Dordrecht: Springer.

Jobbágy, E. G., \& Sala, O. E. (2000). Controls of grass and shrub aboveground production in the patagonian steppe. Ecological Applications, 10, 541-549.

Jung, M., Reichstein, M., Schwalm, C. R., Huntingford, C., Sitch, S., Ahlström, A., ... Zeng, N. (2017). Compensatory water effects link yearly global land $\mathrm{CO}_{2}$ sink changes to temperature. Nature, 541, 516-520. 
Lau, W. K. M., Wu, H. T., \& Kim, K. M. (2013). A canonical response of precipitation characteristics to global warming from CMIP5 models. Geophysical Research Letters, 40, 3163-3169.

Lin, Y.-S., Medlyn, B. E., Duursma, R. A., Prentice, I. C., Wang, H., Baig, S., ... Wingate, L. (2015). Optimal stomatal behaviour around the world. Nature Climate Change, 5, 459-464.

Liu, H., Park Williams, A., Allen, C. D., Guo, D. L., Wu, X. C., Anenkhonov, O. A., ... Badmaeva, N. K. (2013). Rapid warming accelerates tree growth decline in semi-arid forests of Inner Asia. Global Change Biology, 19, 2500-2510.

Lloret, F., \& Granzow-De La Cerda, I. (2013). Plant competition and facilitation after extreme drought episodes in Mediterranean shrubland: Does damage to vegetation cover trigger replacement by juniper woodland? Journal of Vegetation Science, 24, 1020-1032.

Mahmood, T. H., \& Vivoni, E. R. (2014). Forest ecohydrological response to bimodal precipitation during contrasting winter to summer transitions. Ecohydrology, 7, 998-1013.

McDowell, N. G., \& Allen, C. D. (2015). Darcy's law predicts widespread forest mortality under climate warming. Nature Climate Change, 5, 669-672.

McDowell, N., Pockman, W. T., Allen, C. D., Breshears, D. D., Cobb, N., Kolb, T., ... Yepez, E. A. (2008). Mechanisms of plant survival and mortality during drought: Why do some plants survive while others succumb to drought? New Phytologist, 178, 719-739.

Mueller, B., \& Seneviratne, S. I. (2012). Hot days induced by precipitation deficits at the global scale. Proceedings of the National Academy of Sciences of the United States of America, 109, 1239812403.

Novick, K. A., Ficklin, D. L., Stoy, P. C., Williams, C. A., Bohrer, G., Oishi, A. C., ... Philips, R. P. (2016). The increasing importance of atmospheric demand for ecosystem water and carbon fluxes. Nature Climate Change, 6, 1023-1027.

Orlowsky, B., \& Seneviratne, S. (2013). Elusive drought: Uncertainty in observed trends and short- and long-term CMIP5 projections. Hydrology and Earth System Sciences, 17, 1765-1781.

Pederson, N., Dyer, J. M., Mcewan, R. W., Hessl, A. E., Mock, C. J., Orwig, D. A., ... Cook, B. I. (2014). The legacy of episodic climatic events in shaping temperate, broadleaf forests. Ecological Monographs, 84, 599-620.

Peltier, D. M. P., Fell, M., \& Ogle, K. (2016). Legacy effects of drought in the southwestern United States: A multi-species synthesis. Ecological Monographs, 86, 312-326.

Phillips, F. M. (2010). Hydrology: Soil-water bypass. Nature Geoscience, 3 , 77-78.

Piao, S., Nan, H., Huntingford, C., Ciais, P., Friedlingstein, P., Sitch, S., ... Chen, A. P. (2014). Evidence for a weakening relationship between interannual temperature variability and northern vegetation activity. Nature Communications, 5, 5018. https://doi.org/10.1038/ncomm s6018

Pinzon, J. E., \& Tucker, C. J. (2014). A non-stationary 1981-2012 AVHRR NDVI3g time series. Remote Sensing, 6, 6929-6960.

Reichmann, L. G., \& Sala, O. E. (2014). Differential sensitivities of grassland structural components to changes in precipitation mediate productivity response in a desert ecosystem. Functional Ecology, 28, 1292-1298.

Reichstein, M., Bahn, M., Ciais, P., Frank, D., Mahecha, M. D., Seneviratne, S. I., ... Zhao, M. (2013). Climate extremes and the carbon cycle. Nature, 500, 287-295.

Reichstein, M., Ciais, P., Papale, D., Running, S., Viovy, N., Cramer, W., ... Zhao, M. (2007). Reduction of ecosystem productivity and respiration during the European summer 2003 climate anomaly: A joint flux tower, remote sensing and modelling analysis. Global Change Biology, 13, 634-651.

Richard, Y., Martiny, N., Fauchereau, N., Reason, C., Rouault, M., Vigaud, N., \& Tracol, Y. (2008). Interannual memory effects for spring NDVI in semi-arid South Africa. Geophysical Research Letters, 35, L13704. https://doi.org/10.1029/2008GL034119

Sala, O. E., Gherardi, L. A., Reichmann, L., Jobbagy, E., \& Peters, D. (2012). Legacies of precipitation fluctuations on primary production: Theory and data synthesis. Philosophical Transactions of the Royal Society B-Biological Sciences, 367, 3135-3144.

Sala, O., Lauenroth, W., \& Parton, W. (1992). Long-term soil water dynamics in the shortgrass steppe. Ecology, 73, 1175-1181.

Schenk, H. J., \& Jackson, R. B. (2002). The global biogeography of roots. Ecological Monographs, 72, 311-328.

Schwinning, S., Starr, B. I., \& Ehleringer, J. R. (2005). Summer and winter drought in a cold desert ecosystem (Colorado Plateau) part I: Effects on soil water and plant water uptake. Journal of Arid Environments, 60, 547-566.

Sheffield, J., \& Wood, E. F. (2008). Projected changes in drought occurrence under future global warming from multi-model, multi-scenario, IPCC AR4 simulations. Climate Dynamics, 31, 79-105.

Skliris, N., Zika, J. D., Nurser, G., Josey, S. A., \& Marsh, R. (2016). Global water cycle amplifying at less than the Clausius-Clapeyron rate. Scientific Reports, 6, 38752. https://doi.org/10.1038/srep38752

Tang, K., \& Feng, X. (2001). The effect of soil hydrology on the oxygen and hydrogen isotopic compositions of plants' source water. Earth and Planetary Science Letters, 185, 355-367.

Teuling, A. J., Seneviratne, S. I., Stöckli, R., Reichstein, M., Moors, E. Ciais, P., ... Wohlfahrt, G. (2010). Contrasting response of European forest and grassland energy exchange to heatwaves. Nature Geoscience, 3, 722-727.

Tilman, D., \& El Haddi, A. (1992). Drought and biodiversity in Grasslands. Oecologia, 89, 257-264.

Trenberth, K. E., Dai, A., Van Der Schrier, G., Jones, P. D., Barichivich, J., Briffa, K. R., \& Sheffield, J. (2014). Global warming and changes in drought. Nature Climate Change, 4, 17-22.

Van Der Molen, M. K., Dolman, A. J., Ciais, P., Eglin, T., Gobron, N., Law, B. E., ... Wang, G. (2011). Drought and ecosystem carbon cycling. Agricultural and Forest Meteorology, 151, 765-773.

Vanoni, M., Bugmann, H., Notzli, M., \& Bigler, C. (2016). Quantifying the effects of drought on abrupt growth decreases of major tree species in Switzerland. Ecology and Evolution, 6, 3555-3570.

Vesk, P. A., \& Westoby, M. (2003). Drought damage and recovery-A conceptual model. New Phytologist, 160, 7-14.

Vicente-Serrano, S. M., Gouveia, C., Camarero, J. J., Beguería, S., Trigo, R., López-Moreno, J. I., ... Sanchez-Lorenzo, A. (2013). Response of vegetation to drought time-scales across global land biomes. Proceedings of the National Academy of Sciences of the United States of America, 110, 52-57.

Will, R. E., Wilson, S. M., Zou, C. B., \& Hennessey, T. C. (2013). Increased vapor pressure deficit due to higher temperature leads to greater transpiration and faster mortality during drought for tree seedlings common to the forest-grassland ecotone. New Phytologist, 200, 366-374.

Williams, A. P., Allen, C. D., Macalady, A. K., Griffin, D., Woodhouse, C. A., Meko, D. M., ... McDowell, N. G. (2013). Temperature as a potent driver of regional forest drought stress and tree mortality. Nature Climate Change, 3, 292-297.

Wolf, S., Keenan, T. F., Fisher, J. B., Baldocchi, D. D., Desai, A. R., Richardson, A. D., ... Van Der Laan-Luijkx, I. T. (2016). Warm spring reduced carbon cycle impact of the 2012 US summer drought. Proceedings of the National Academy of Sciences of the United States of America, 113, 5880-5885.

Wu, X., Liu, H., Li, X., Liang, E., Beck, P. S., \& Huang, Y. (2016). Seasonal divergence in the interannual responses of Northern Hemisphere vegetation activity to variations in diurnal climate. Scientific Reports, 6, 19000. https://doi.org/10.1038/srep19000

Wu, D., Zhao, X., Liang, S., Zhou, T., Huang, K., Tang, B., \& Zhao, W. (2015). Time-lag effects of global vegetation responses to climate change. Global Change Biology, 21, 3520-3531. 
Yaseef, N. R., Yakir, D., Rotenberg, E., Schiller, G., \& Cohen, S. (2010). Ecohydrology of a semi-arid forest: Partitioning among water balance components and its implications for predicted precipitation changes. Ecohydrology, 3, 143-154.

Zwieniecki, M. A., \& Holbrook, N. M. (2009). Confronting Maxwell's demon: Biophysics of xylem embolism repair. Trends in Plant Science, 14, 530-534. 